\title{
Medical Physics in Expertia Program
}

Jiménez, F Javier ${ }^{\text {ab }}$; García, Eduardo ${ }^{a}$; Ponce, J Miguel ${ }^{\text {c}}$; Gascón, Marina ${ }^{\text {c }}$; Puertas, M Mar ${ }^{c}$; and Méndez, Agustina ${ }^{c}$

${ }^{a}$ Atomic, Molecular and Nuclear Section, Theoretical Physics Department, University of Zaragoza, Spain, ${ }^{b}$ Medical Physics and Radiation Protection Unit, University Hospital "Miguel Servet", Spain 'Radiation Oncology Unit, University Hospital "Miguel Servet", Spain.

\begin{abstract}
Dosimetry and Radiation Protection, and Nuclear Physics and Technology are among the optional subjects in the degree in Physics of the University of Zaragoza. Both of them are taught by the Atomic, Molecular and Nuclear Area in the Faculty of Science. Since 2010, teaching staff on these subjects started to collaborate with a Medical Physics expert. The collaboration consisted of a seminar on Medical Physics and a guided tour to the clinical facilities. In these activities, the main tasks of a Medical Physicist and the way to access to the specialized training were explained. In 2015 University of Zaragoza launched the first call of the Expertia Program. This educational program adds professional experience to the academic programs. Since then, the teaching staff on Dosimetry and Radiation Protection, and Nuclear Physics and Technology have applied for the Educational Expertia (Expertia Docente) Program in all the editions and the collaboration has been enlarged to include several Radiation Oncologists' experiences in the activities.
\end{abstract}

Keywords: Medical Physics; Expertia Program; Radiation Protection. 


\section{Introduction}

Medical Physics is a significant area of work for graduates in Physics. It can be broadly defined as a field in which applied physics techniques are used in medicine (Seuntjens, 2006). In particular, Medical Physics has traditionally dealt with ionizing radiation issues in the diagnosis and treatment of diseases. The Medical Physics expert is defined in the Medical Exposure Directive, 97/43/Euratom (European Commission, 1997) as an expert in his own right with a well-defined professional role. The European Commission stablished the European guidelines on Medical Physics expert (European Commission, 2014).

In Spain, students with a bachelor's degree in scientific or technical areas can access to certified specialized training programs passing an entry exam (MSC\&MEC,1996). In this case, they join a three-year academic program of a certified healthcare center as resident physicist. After completion of this specialized training, they receive the corresponding certification for clinical Medical Physics practice.

An approach to Medical Physics is offered to students through training programs on Biophysics' or Bioengineering's degrees, as well as on Physics' degree. In particular, at the University of Zaragoza, students on the degree in Physics can enroll in the courses of Dosimetry and Radiation Protection, and Nuclear Physics and Technology, optional subjects that offer a first contact with Medical Physics. (for details about the subjects see their corresponding teaching guides on https://estudios.unizar.es) These two subjects are taught by the Atomic, Molecular and Nuclear Area of the Faculty of Science. They cover, among others, theoretical and phenomenological aspects of clinical dosimetry, clinical radiation sources, clinical radiation devices, or radiation protection in healthcare facilities. According to the Standards and Guidelines for Quality Assurance in the European Higher Education Area (ESG, 2015), the teaching staff on these subjects encourage innovation in teaching methods. To do this, and in order to motivate students, they decided to include external experienced point of views. In this way, the theoretical and phenomenological aspects of the subjects could be complemented with external professional experiences which emphasize that Medical Physics is a physics field (in hospitals, industries, research laboratories, etc.) offering students a job opportunity and, in the long term, a specialization on which to develop their career.

As a result, in 2010, a Medical Physics expert started to collaborate with them in an informal way. The collaboration consisted of a seminar on Medical Physics and a visit to the corresponding clinical facilities of a hospital. In these activities, the main duties of a Medical Physicist and the way to access to the specialized training were explained. The fine reception given to these complementary activities encouraged to hold them every year.

In 2015 University of Zaragoza launched the first call of the Expertia Program (Unizar, 2017). This educational program adds professional experience to the academic programs. 
The teaching staff of the University of Zaragoza can join to the Expertia Program through their Faculty or Center, and lay on institutional or business experiences to share with their students. It was an excellent opportunity to formally organize and consolidate the abovementioned external activities. Since this first call in 2015, the Medical Physics expert collaboration is framed in the Expertia Program. In this new more formal framework, several radiation oncologists' experiences have been added to the collaboration activities.

\section{Material and methods}

\subsection{Main features of Expertia Program}

The Expertia Program (see FEUZ 2017 for the last call) has been developed by Zaragoza Company University Foundation (Fundación Empresa Universidad de Zaragoza, FEUZ), aiming to strengthen cooperation between the field of university education and the business world.

The Expertia Program opens windows from the subjects corresponding to the studies of degree, university masters and doctorate to present the vision that the Society has in both, the academic disciplines and the entrepreneurial opportunities. The Expertia Program also promotes the adaptation of the university students' training to the current requirements of the labour and professional market. Another feature of Expertia Program is to foster entrepreneurial attitudes.

The Program is carried out by professionals from the field of the companies and institutions as well as by entrepreneurs who have started a business activity.

There are to two Program modalities: Expertia Docente (Educational) and Expertia Emprendedor (Enterpreneurial). The teaching staff on Dosimetry and Radiation Protection, and Nuclear Physics and Technology chose the former modality. In Expertia Docente, external professionals (from companies or institutions) give lectures and present to university students real cases related to their professional experience and to the topics of their official curriculum. These activities match with the already existing collaboration between a Medical Physics expert and teaching staff of the Atomic, Molecular and Nuclear Area of the University of Zaragoza.

All the University of Zaragoza teaching staff giving classes in first or second cycle of the Physics degree, in masters or in doctoral studies, and interested on enhancing teaching with external experts' point of view can apply for a collaboration activity. The application can be submitted once a year to the corresponding Faculty or Center. Each Faculty/Center submits to FEUZ a global request including applications from all the degrees. The Evaluation Committee, composed of the Academic Vice Rector of the University of Zaragoza, the 
Director of FEUZ, and all the Faculty Deans / Center Directors who have submitted a global application, reviews all the requests and approves those fulfilling the requirements for elegibility.

When the activities that have been approved by the Evaluation Committee are finished, the professor in charge of the activity sends to FEUZ a report about the completion of the proposed activities. Deadline for sending this report is a month since the activity has been carried out. With this report, FEUZ proceeds to send a certificate to the professionals who have participated on Expertia Program.

\subsection{Expertia Program on Medical Physics}

Teaching staff on Dosimetry and Radiation Protection, and on Nuclear Physics and Technology submitted requests to the three calls for proposals launched by the Expertia program up to now. The proposed activities included seminars conducted by two professionals from Servicio Aragonés de Salud (Salud), a Medical Physics expert and a Radiation Oncology expert, and a guided tour through the Medical Physics and Radiation Oncology facilities at University Hospital "Miguel Servet”. All the requests were approved by FEUZ and the different activities were carried out.

Seminar duration is approximately four hours, including discussion, and its contents are the following:

First, the Medical Physics expert presents his/her main duties in a hospital in absolute manner. These duties are grouped according to the hospital units where ionizing radiation is used, namely, Nuclear Medicine, X-ray Diagnosis, Radiation Oncology, and Hospital Radiation Protection. He/she gives details about the kind of radiation used, radiation sources or generators, measurement devices, and main purposes of radiation used on each area.

Next, the Radiation Oncology expert exposes the radiotherapy treatment steps from a clinical point of view. The sequence of steps is the following: Radiation Oncology Expert visit, localization images acquisition for planning the treatment (computed tomography, nuclear magnetic resonance, ecography, positron emission tomography, angiography,...), the medical treatment planning, the patient dosimetry evaluation from a clinical point of view, the treatment start-up, the treatment delivery and secondary effects of the treatment, and the dosimetric and clinical reviews after treatment. The Medical Physics expert also participates in the presentation explaining the physical aspects on the steps in which he/she participates: localization images acquisition for planning the treatment, the treatment planning, the patient dosimetry evaluation, the treatment start-up, the treatment delivery, and the dosimetric reviews after treatment. This second part of the seminar highlights the 
interdisciplinarity on all over the process and the great synergy among all professionals who get involved in the radiotherapy process.

After that, the Medical Physics expert talks about the access to the specialized training on Medical Physics in Spain: procedure, official publication of the call, the exam and its contents, the number of posts offered each year and its historical evolution, etc. In addition, he provides relevant links to web pages of the Ministry of Education (Ministerio de Educación, Cultura y Deporte), the Spanish Society of Medical Physics (Sociedad Española de Física Médica), the Nuclear Safety Council (Consejo de Seguridad Nuclear), where students can widen this information.

The seminar closes with a forum to discuss with students the different issues raised and to solve their questions.

The second part of the collaboration, a guided tour in hospital facilities of approximately 3 hours, is conditioned upon clinical availability. When possible, the facilities visited have been: the Medical Physics and Radiation Protection Unit, and the Radiation Oncology Unit. In order to follow the Protection of Personal Data all the participants in the guided tour must previously sign a Confidentiality Protocol.

In the Medical Physics and Radiation Protection Unit the treatment planning systems for radiotherapy treatments are showed, as well as radiation measurement devices and phantoms used in quality controls in Nuclear Medicine, X-ray Diagnostic or Radiation Oncology. The Medical Physics expert discusses with students a real treatment planning, and its main aspects like the kind of radiation, energy, dose prescription and dose limits.

In the Radiation Oncology Unit, students follow the sequential treatment steps. They start in the consulting room where the first Radiation Oncology expert visit takes place. The next point is an imaging device, the computed tomography room, where the laser localization system, immobilization devices and patient positioning are explained. After that, they go to a treatment room where they can see a clinical linear accelerator. The Medical Physics expert details its main features and the radiation protection systems, and carries out a daily test for quality control of the accelerator.

These activities, whose objectives are motivate, stimulate and provide information to students about the Medical Physics field, are offered to them as voluntary and its contents are not included in the assessment of the corresponding subjects.

\section{Results}

In the first edition of Expertia Program (course 2015-16), 23 students of Nuclear Physics and Technology and 14 of Dosimetry and Radiation Protection participated. This 
corresponds to $85 \%$ and $93 \%$ of the enrolled students, respectively. In this edition both, the four-hour seminar and the three-hour guided tour were carried out.

In the second edition (course 2016-17), 16 students of Nuclear Physics and Technology and 11 of Dosimetry and Radiation Protection joined to the Expertia Program. This means a similar percentage of students: $84 \%$ and $92 \%$, respectively. In this edition, only the fourhour seminar could be carried out.

For the current edition (course 2017-18) the seminar has been carried out with 11 students of Nuclear Physics and Technology and 5 of Dosimetry and Radiation Protection which means percentages of $92 \%$ and $50 \%$, respectively. At the time of writing this paper, a guided visit to the University Hospital "Miguel Servet" has been carried out for a reduced number of students. In the previous editions some students had expressed their satisfaction with the activities of the program to the teachers. In this edition, an anonymous survey has been designed to gather the students' opinion, and perform a qualitative analyse at the end of the academic course.

The percentage participation during these years has been very high (see Figure 1) except for the students of Dosimetry and Radiation Protection this year (only 50\%). In any, this decrease in the percentage attendance of students is not very significant due to the low number of students enrolled this year in the subjet (only 10 students). The overall participation showed in Figure 1 with solid pattern bars, is above $70 \%$ every year.

In the forum that follows the talks of the seminar, we have observed that most of the students are not aware of the possibility of working in hospitals as physicists. They are very surprised with the variety of duties and responsibilities of a Medical Physics expert and with his/her continuous and so close collaboration with oncologists, surgeons, technicians and other hospital staff. Among the questions most frequently addressed during the forum discussion are those regarding the access to the profession (topics covered by the civil service examination, the most difficult aspects, how to prepare the examination, etc.), and about the workday and future career of a Medical Physics expert. They are also very interested in job opportunities in the day-by-day relationship with patients, and in the possibility to develop in parallel a research career. At this point, it is important to mention that this activity out of classes intends to attract students not only to the profession of Medical Physics expert, but also to the Medical Physics field in general (research, industries, radiological protection private companies, etc.).

As a result of the activity, several students have asked to UNIVERSA (an Orientation and Employment Service of the University of Zaragoza) for internship at University Hospital "Miguel Servet". Until now, seven students have successfully completed an internship in the Medical Physics and Radiation Protection Unit. This internship is non-remunerated, and consists on a stay in the Radiation Protection Unit at University Hospital "Miguel Servet". 
The internship length depends on the Unit availability. Currently this length uses to be 100 hours, but sometimes it has been extended to 240 hours. Within the agreed time period the student goes with the Medical Physics experts while they are working, and he/she can be asked to do some task, but always under a Medical Physic expert's supervision. The student has a tutor from Faculty of Science who endorses the internship application, and another tutor from the Medical Physics and Radiation Protection Unit who schedules the student activities taking into account the unit calendar. The student spends about half his/her time on external radiotherapy issues, $30 \%$ on brachytherapy, $7 \%$ on nuclear medicine, $7 \%$ on Xray diagnostic, and $6 \%$ on radiation protection. The student is invited to give a presentation about his/her internship to the unit staff. Finally, the tutor of the hospital unit has to fill out a UNIVERSA form to evaluate the student attitude during the internship. Students can also request the recognition of academic credits (up to 5 ECTS in the case of the degree in Physics) for the internship. To do so, they have to provide a detailed report of the activity and the academic tutor has to fulfil a rating form.

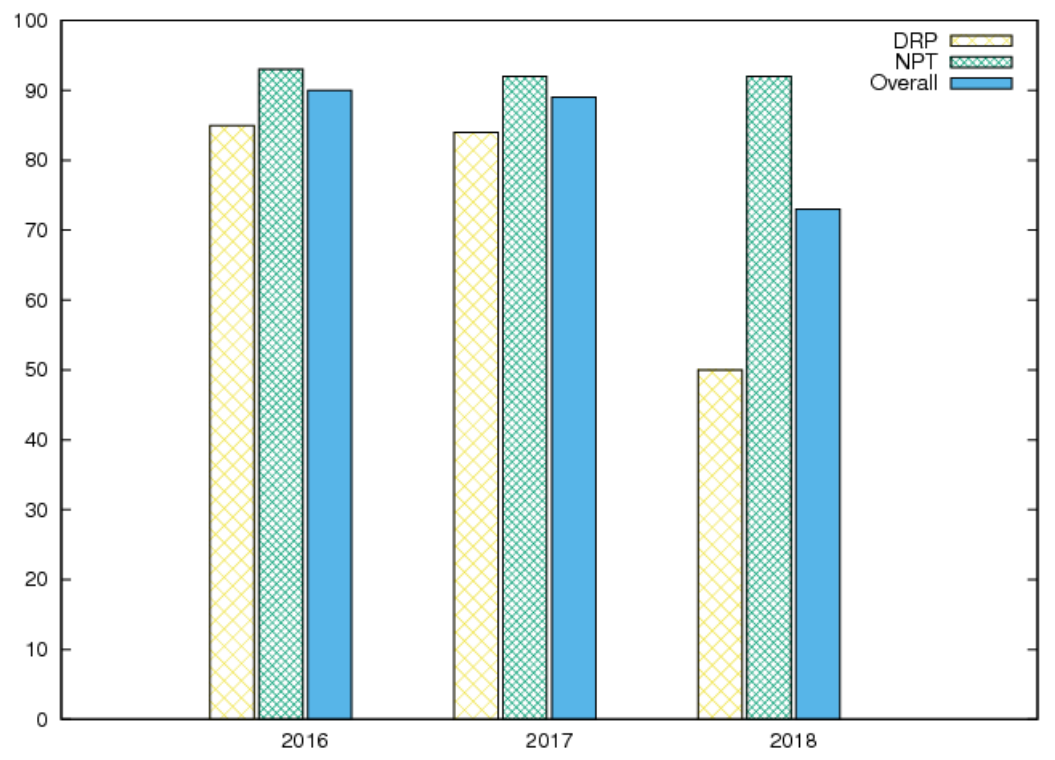

Figure 1. Percentage participation to the Expertia Program, by subject ( DRP: Dosimetry and Radiation Protection; NPT: Nuclear Physics and Technology; Overall) and year.

\section{Conclusions}

The Educational Expertia Program (Expertia Docente) has served to consolidate and give a formal framework to the collaboration started in 2010 among a Medical Physics expert of 
the University Hospital "Miguel Servet" and teaching staff of the Atomic, Molecular and Nuclear Area of the Faculty of Science of the University of Zaragoza.

The activities include the description of the access, training and duties of a Medical Physics expert, the full process of radiotherapy, and the different devices for radiation measurement, medical imaging and treatment. The program intends to increase the interest on Medical Physics among students of the degree in Physics, and to show Medical Physics field as a career opportunity.

Students satisfaction with Expertia Program in the three editions carried out has been very high, with an average on overall participation of approximately $80 \%$ of students. The activities met the students expectations. Moreover, up to now seven students have carried out an internship in the Medical Physics and Radiation Protection Unit of the University Hospital "Miguel Servet". In the next years it is foreseen the continuation of the programme and a similar participation is expected.

\section{Acknowledgements}

The authors would like express many thanks to Fundación Empresa Universidad de Zaragoza (FEUZ) for its confidence in our project. The authors also wish to express gratitude to University Hospital "Miguel Servet" for making easier the guided tour through its facilities. This work is dedicated to Professor J.A. Villar of the University of Zaragoza, the initiator of this collaboration, who passed away in August, 2017.

\section{References}

European Commission. (1997). Council Directive 97/43/Euratom of 30 June 1997 on health protection of individuals against the dangers of ionising radiation in relation to medical exposures. Official Journal of the European Communities

European Commission. (2014) Radiation Protection No 174. European Guidelines on Medical Physics Expert

Fundación Empresa Universidad de Zaragoza, (FEUZ, 2017). FEUZ-Expertia Program. Retrieved from http://www.feuz.es/en/services/training/expert-partner-network/expertiaprogram

Ministerio de Sanidad y Consumo and Ministerio de Educación y Ciencia, (1996). Guía de Formación de Especialistas. Separata: Radiofísica Hospitalaria

Seuntjens, J. (2006). Medical physics in Current Oncology. Current Oncology, 13(2), 46.

Standards and Guidelines for Quality Assurance in the European Higher Education Area (ESG). (2015). Brussels, Belgium

University of Zaragoza (Unizar, 2017). 3rd EXPERTIA Program Call. Retrieved from https://www.unizar.es/institucion/vicerrectorado-de-profesorado/3a-convocatoriaprograma-expertia 